\title{
La creación de la carrera de Sociología en la UNL
}

\author{
Silvia Montenegro ${ }^{(1)}$
}

(1) Coordinadora de la carrera. (2) Podemos sugerir, entre varias lecturas posibles, la biografía de Gino Germani, escrita por su hija, Germani,

A. Gino Germani. Del antifascismo a la sociología, Buenos Aires, Taurus, 2004 o el artículo de Sidicaro,

R. "Reflexiones sobre la accidentada trayectoria de la sociología en la Argentina”, Cuadernos Hispanoamericanos No 517, Madrid, 1993.
Son pocas las carreras de sociología que existen en Argentina, la más antigua es la de la Universidad de Buenos Aires, que en el 2007 celebró los 50 años de su creación. Otras carreras, de diversa antigüedad, pertenecen a las Universidades Nacionales de Santiago del Estero, Cuyo, San Juan, Comahue y La Plata, a las que se sumaron en los últimos dos años las licenciaturas de la Universidad Nacional de General San Martín y la reapertura de la carrera de la Universidad Nacional de Mar del Plata, cerrada en 1977 por la dictadura militar.

La institucionalización de la sociología no ha sido una tarea fácil en nuestro país, incluso hay quienes afirman que se trata de un proceso inconcluso, basta pasar revista a algunos estudios sobre el tema para conocer los laberintos de dicho proceso ${ }^{(2)}$. No obstante, el contexto de creación de la carrera de sociología en la Universidad Nacional del Litoral es, en términos comparativos, más auspicioso que el que signara a las carreras más antiguas del país. En nuestro medio las iniciativas para su creación partieron del reconocimiento de que su implementación constituía una necesidad de la re- 
gión litoral, las mismas se remontan a una década atrás, cuando en 1997 el H. Consejo Superior dictó la Resolución № 167 que disponía promover la creación de la carrera, a la que se sumó en 2000 la Resolución № 60 por la que se encomendaba a la Secretaría Académica la realización de un estudio de factibilidad en torno a la implementación de la carrera en nuestro medio. En ese momento ofició como consultor el actual profesor de nuestra carrera Ricardo Sidicaro, quien concluyó que era propicia y factible su creación. En tal sentido, quisiera destacar algunos puntos señalados en su informe, dado que resumen aspectos centrales: el contextual, el vinculado a la inserción profesional y el de la necesidad de construir una carrera que parta del reconocimiento del actual carácter polifónico de la disciplina:

"Con el retorno al libre funcionamiento de las instituciones democráticas para la sociología universitaria se abrió, también, una nueva etapa. (...) No es, pues, una afirmación de compromiso sostener que, sociológicamente hablando, existen buenas condiciones sociales, políticas y académicas para iniciar una nueva carrera universitaria de sociología. (...) La demanda de sociólogos tanto del sector público como del privado ha hecho que en los últimos años no se pueda considerar que la situación profesional de los mismos sea más difícil que la de los graduados de otras carreras universitarias. (...) Sería imposible abordar la manera en que se amplió la agenda temática de la que hoy se ocupan las investigaciones de la sociología. Digamos al respecto que la fragmentación que es propia de las sociedades contemporáneas, debía conducir naturalmente a la multiplicación de los focos de interés de las investigaciones sociológicas. A ello se sumó la denominada crisis de los "grandes relatos" que despejó el panorama de las ideas y creencias que en otras épocas habían encontrado en la sociología un lugar propicio para establecerse y repetir en su seno discursos más propios de la filosofía o de la historia de las ciencias sociales. El antes mencionado carácter polifónico de la sociología contemporánea contribuyó, también, a que se multipliquen los objetos de conocimiento"(3).
(3) Sidicaro, R. (2000) Informe sobre la factibilidad de creación de una carrera de sociología en la UNL. 
Una vez elaborado el plan de estudios actualmente vigente se abrió la inscripción, primero en una forma que podríamos llamar "experimental", ya que estaba destinada a estudiantes que estuviesen inscriptos en otras carreras de la UNL. Fue al año siguiente, en 2003, cuando se abrió la matriculación e ingresó la segunda cohorte que hoy cursa las últimas asignaturas de la carrera. El primer año no ofrecía mayores dificultades, integrado por asignaturas ya existentes y comunes a diversas carreras fue cubierto por docentes de la casa que se desempeñaban frente a las mismas. Más adelante debió comenzar a sortearse el desafío de contar con recursos humanos con formación específica en el área, en el marco de una disciplina que por primera vez se dictaba en la región. Actualmente, puede decirse que el objetivo de su implementación ha sido cumplido y que la carrera debe encaminarse hacia otros desafíos, relacionados al afianzamiento del desarrollo de la investigación, inherente y fundamental a la disciplina sociológica, y a la vinculación con sectores gubernamentales, de la producción y de la comunidad en general. Desde el año 2006 la carrera de sociología de UNL forma parte de la Red de Carreras de Sociología y Cursos de Ciencias Sociales de Argentina, impulsada en oportunidad de las Jornadas Preparatorias del Congreso de la Asociación Latinoamericana de Sociología (PreALAS), realizadas en la Universidad Nacional de Cuyo en noviembre de ese año. Ese instrumento ha permitido interactuar en reuniones diversas con las otras carreras del país, con el objetivo de debatir proyectos conjuntos, potenciar logros y participar, en forma también conjunta, en la organización de eventos académicos.

Para concluir, cabe agregar que una síntesis de esta naturaleza no hace justicia a todos los actores que desde su creación hasta ahora han participado de este proyecto -los claustros docentes, estudiantiles y las gestiones de las dos facultades a las que la carrera pertenece- desde la firme creencia de que este proyecto, innovador e inédito para nuestro medio, era posible. 